\title{
BMJ Open Small volume plasma exchange for Guillain-Barré syndrome in resource- limited settings: a phase II safety and feasibility study
}

\author{
Badrul Islam, ${ }^{1,2}$ Zhahirul Islam, ${ }^{2}$ Shafiqur Rahman, ${ }^{3}$ Hubert P Endtz, ${ }^{1}$ \\ Margreet C Vos, ${ }^{1}$ Mathieu van der Jagt, ${ }^{4}$ Peter A van Doorn, ${ }^{5}$ Bart C Jacobs, ${ }^{6}$ \\ Quazi Deen Mohammad ${ }^{7}$
}

To cite: Islam B, Islam Z, Rahman S, et al. Small volume plasma exchange for GuillainBarré syndrome in resourcelimited settings: a phase II safety and feasibility study. BMJ Open 2018;8:e022862. doi:10.1136/ bmjopen-2018-022862

- Prepublication history and additional material for this paper are available online. To view these files, please visit the journal online (http://dx.doi. org/10.1136/bmjopen-2018022862).

Received 22 March 2018 Revised 8 June 2018 Accepted 12 June 2018

Check for updates

(C) Author(s) (or their employer(s)) 2018. Re-use permitted under CC BY-NC. No commercial re-use. See rights and permissions. Published by BMJ.

For numbered affiliations see end of article.

Correspondence to

Dr Badrul Islam;

badrul.islam@icddrb.org

\section{ABSTRACT}

Objective To assess the safety and feasibility of small volume plasma exchange (SVPE) for patients with GuillainBarré syndrome (GBS).

Design Non-randomised, single-arm, interventional trial. Setting National Institute of Neurosciences and Hospital, Dhaka, Bangladesh.

Participants Twenty adult (>18 years) patients with GBS presented within 2 weeks of onset of weakness who were unable to walk unaided for more than $10 \mathrm{~m}$.

Interventions SVPE involves blood cell sedimentation in a blood bag and removal of supernatant plasma after blood cells are retransfused. This procedure was repeated three to six times a day, for eight consecutive days. Fresh frozen plasma (FFP) and normal saline were used as replacement fluid.

Outcome measures Serious adverse events (SAEs) were defined as severe sepsis and deep venous thrombosis related to the central venous catheter (CVC) used during SVPE. SVPE was considered safe if less than $5 / 20$ patients experienced an $\mathrm{SAE}$, and feasible if $8 \mathrm{~L}$ plasma could be removed within 8 days in at least $15 / 20$ patients.

Results Median patient age 33 years (IQR 23-46; range 18-55); 13 (65\%) were male. Median Medical Research Council (MRC) sum score was 20 (IQR 0-29; range 0-36); three $(15 \%)$ patients required mechanical ventilation. One patient developed SAE (severe sepsis, possibly related to CVC). The median plasma volume exchanged was $140 \mathrm{~mL}$ $\mathrm{kg}$ (range 110-175) and removal of 8L plasma was possible in $15(75 \%)$ patients. Patients received a median $1 \mathrm{~g} / \mathrm{kg} \mathrm{lgG}$ via FFP although a substantial proportion of IgG was probably removed again by the SVPE sessions. GBS disability score improved by at least one grade in 14 (70\%) patients 4 weeks after SVPE started. No patients died.

Conclusion SVPE seems a safe and feasible alternative treatment to standard plasma exchange (PE) or intravenous immunoglobulin (IVIg) for GBS; further studies of clinical efficacy in low-income and middle-income countries are warranted.

Trial registration number NCT02780570.

\section{INTRODUCTION}

Guillain-Barré syndrome (GBS) is an acute immune-mediated polyradiculoneuropathy
Strengths and limitations of this study

- The strength of this study underlies the novel and simple technique of small volume plasma exchange (SVPE), which is much less expensive than conventional immunotherapies (plasma exchange (PE) and intravenous immunoglobulin (IVIg)).

- SVPE is corroborated as safe and feasible for the first time in a prospective and standardised cohort of patients with Guillain-Barré syndrome (GBS).

- The intrinsic limitations of this study are its non-randomised, single-arm nature, which is conducted in a single centre with a limited sample size of patients with GBS. The volume exchanged was at the lower range compared with previous $\mathrm{PE}$ studies conducted in GBS.

- Clinical efficacy of SVPE on patients with GBS was a secondary endpoint assessment and therefore deserves a randomised controlled trial in future to assess the clinical efficacy of SVPE for the patients with GBS.

with a yearly incidence of 1.2-2.3 cases per 100000 per year. ${ }^{1}$ GBS is characterised by rapidly progressive limb weakness and, in a proportion of cases, respiratory failure (25\%) or severe autonomic dysfunction (10\%). Plasma exchange (PE) was the first treatment proven to be effective for GBS, if given within 4 weeks of the onset of weakness. ${ }^{2-11}$ Conventionally for patients with GBS, three to five plasma exchange (PE) sessions are done in alternate days within a span of 7-14 days targeting a PE rate of $120-200 \mathrm{~mL} / \mathrm{kg}$ (40-50 mL/kg/day). ${ }^{7}$ Later studies showed treatment with intravenous immunoglobulin (IVIg) $(0.4 \mathrm{~g} / \mathrm{kg}$ per day for 5 days) has a similar efficacy as PE in patients with GBS who are unable to walk, if started within 2 weeks of the onset of weakness. ${ }^{12} 13$

Unfortunately, most patients in low-income countries cannot afford expensive 
treatment with either PE or IVIg. ${ }^{14}$ In Bangladesh, a full course of IVIg for a $60 \mathrm{~kg}$ adult costs approximately US $\$ 12000-U S \$ 16000$ and treatment with conventional PE for 5 days costs approximately US $\$ 4500-U S \$ 5000$. The mean income in Bangladesh was US $\$ 4$ per day in 2016 (World Bank and Bangladesh Bureau of Statistics 2016); IVIg and PE cost the equivalent of 4,000 and 1250 mean income days, respectively. At present, the majority $(92 \%)$ of patients with GBS in Bangladesh receive supportive care only. ${ }^{14}$ In addition, mobile PE equipment is not available in Bangladesh; therefore, patients admitted to the intensive care unit (ICU) cannot receive PE. We previously reported the mortality rates for GBS in Bangladesh range from $12 \%$ to $14 \%$ and observed $29 \%$ of patients with GBS in Bangladesh are unable to walk at 6 months after onset; these poor outcomes are undoubtedly due to the low rates of specific treatment with PE or IVIg. ${ }^{15} 16$

Small volume plasma exchange (SVPE) may represent a cheap, effective alternative treatment for GBS. SVPE is based on the same principle as conventional PE (selective removal of plasma) but uses a novel, simple technique with much lower costs (approximately US\$500). The current non-randomised trial was designed to investigate the safety and feasibility of SVPE in 20 patients with GBS admitted to the National Institute of Neurosciences Hospital (NINS) in Dhaka, Bangladesh.

\section{METHODS/DESIGN}

\section{Study design}

For this non-randomised, single-arm, interventional safety and feasibility trial, 20 adult patients with GBS were enrolled between March 2016 and December 2016 for SVPE at the NINS, Dhaka, Bangladesh. A detailed study protocol was published previously and includes definitions of all variables used in this study. ${ }^{17}$

Four to six daily sessions of whole blood sedimentation and removal of supernatant plasma after retransfusion of the sedimented blood cells were planned for the 20 patients with GBS, with a target of removing an overall volume of at least $8 \mathrm{~L}$ of plasma over a total of 8 days ${ }^{17}$ (see online supplementary video for SVPE procedure).

Patients with GBS were monitored according to a standard protocol throughout the course of SVPE until the second day after withdrawal of the central venous catheter (CVC) in order to assess predefined measures of safety and feasibility and followed up for 6 months to assess neurological outcome. and The protocol is registered at ClinicalTrials.gov (NCT02780570). ${ }^{17}$

\section{Patient and public involvement}

Patients and or public were not involved either in the development of the research question, study design and outcome measure or recruitment to and conduct of the study.

\section{Inclusion and exclusion criteria for patients with GBS}

Patients aged $\geq 18$ years old fulfilling the diagnostic criteria for GBS of the National Institute of Neurological and Communicative Disorders and Stroke ${ }^{18}$ were enrolled, provided they were unable to walk unaided for more than $10 \mathrm{~m}$ (GBS disability score $\geq 3$ ), presented within 2 weeks of the onset of weakness and were unable to afford standard treatment with IVIg or PE. Patients with concomitant severe or terminal illnesses, evidence of healthcare-associated infection (HAI) on admission (except for aspiration pneumonia), a previous history of severe allergic reactions to properly matched blood products and pregnant women were excluded from the study.

\section{Control cohort}

To compare the safety of SVPE in patients with GBS in the context of the background risk of central line-associated blood stream infection (CLABSI) at our institution, we prospectively assessed the incidence of CLABSI in a hospital control group of 24 adult patients without GBS receiving neurocritical care. Hospital controls were eligible based on the following characteristics: $\geq 18$ years old, a neurological diagnosis other than GBS and a CVC placed for $>2$ and $\leq 8$ calendar days after admission to the same intensive care unit (ICU) or high dependency unit (HDU) unit as the SVPE-treated patients. Patients with an HAI (except aspiration pneumonia) and pregnant women were excluded from the control group.

\section{Primary and secondary outcome measures}

The primary outcome measures of safety were the number of patients with GBS treated with SVPE who developed either severe sepsis or septic shock due to CLABSI ${ }^{19}$ and the occurrence of venous thrombosis in the limb where the CVC was placed. The primary outcome measure of feasibility was the ability to remove at least $8 \mathrm{~L}$ of plasma over 8 days.

The secondary outcome measures of the safety of SVPE were the relative risk of CLABSI due to SVPE (compared with CLABSI in the hospital control group without GBS), haemodynamic instability during the SVPE procedure and development of anaemia (haemoglobin, $(\mathrm{Hb})<8 \mathrm{~g}$ / $\mathrm{dL}$ ) or any catheter-related haemorrhage requiring a blood transfusion.

The secondary outcome measure of feasibility of SVPE was the rate of CVC occlusion during the SVPE procedure. In addition, neurological outcome was assessed using the GBS disability score,${ }^{20}$ Medical Research Council (MRC) sum score,${ }^{21}$ Overall Neuropathy Limitation Scale (ONLS) ${ }^{22}$ and Rasch-built Overall Disability Scale (R-ODS) ${ }^{23}$ at 1st, 2nd, 3rd and 6th months from the start of SVPE.

\section{Procedure safety documentation and cost of SVPE}

Strict aseptic procedures were followed to prevent CLABSI. ${ }^{24-26}$ SVPE was documented in terms of the duration and amount of plasma removed in each session, and the type and volume of replacement fluid and fresh 
frozen plasma (FFP) used. Throughout the procedure, the haemodynamic, haematological, biochemical, coagulation and infection profiles of the SVPE-treated patients were monitored according to the protocol. ${ }^{17}$ Screening for hepatitis B and C viruses, HIV and syphilis were performed as patient baseline assessments, and also on donor FFP before administration. CLABSI, primary and secondary bloodstream infections, ${ }^{19}$ catheter-associated urinary tract infection (CAUTI), ${ }^{27}$ ventilator-associated pneumonia (VAP) ${ }^{28}$ and other $\mathrm{HAI}^{29}{ }^{30}$ were documented in the SVPE-treated patients with GBS and the hospital control group. Expenditure for the full course of SVPE will be approximately US $\$ 500$ (fresh frozen plasma (FFP (24 bags)=US $\$ 240$, blood bag and saline sets: US $\$ 40$, low-molecular-weight heparin: US\$110, routine investigation: US\$50, saline: US $\$ 10$, CV catheter: US $\$ 40=$ total US $\$ 490)$.

\section{Sample size}

This safety and feasibility study enrolled 20 patients with GBS for SVPE. We could not perform a formal power calculation for this safety and feasibility study. The sample size was based on previous pilot studies conducted in GBS. ${ }^{31} 32$ The baseline rate of CLABSI was measured in the hospital control group of 24 patients without GBS admitted to the same study facility who required a CVC for at least 8 days during the study period.

\section{Stopping rules for the trial based on safety and feasibility}

Decision to stop the SVPE trial was designated using a Bayesian approach. ${ }^{33-35}$ Accordingly, a predictive success rate of $75 \%$ was predefined for the SVPE procedure. If more than 5 of 20 patients experienced a serious adverse event (SAE), or if it appeared impossible to remove at least $8 \mathrm{~L}$ of plasma over 8 days in at least 15 of 20 patients, the procedure was considered unsafe or not feasible.

\section{Statistical analysis}

The rates of HAIs (CLABSI, VAP and CAUTI) per 1000 device days were calculated by dividing the number of each HAI during the study period by the number of device days and multiplying the result by 1000 . The infection safety profile for SVPE was assessed by calculating the standardised infection ratio (SIR) to define the risk of HAIs in patients with GBS treated with SVPE. The SIR was calculated by dividing the number of observed HAI by the number of HAI predicted (ie, the infection rate in the control group). The predicted HAI rate was calculated using the rates of HAI in the hospital control group of patients without GBS during the study period. Percentage values were compared using the $\chi^{2}$ test or Fisher's exact test (two tailed) and median values, the Mann-Whitney U test using SPSS V.22.0 (IBM SPSS). Analyses were performed on an intention-to-treat basis. All $\mathrm{p}$ values reported are two sided; $\mathrm{p}<0.05$ was considered significant.
Table 1 Demographic and clinical characteristics of the 20 patients with GBS included in this small volume plasma exchange study at entry

\begin{tabular}{lc}
\hline Characteristic & Values \\
\hline Demography & $13: 7(1.85)$ \\
\hline Sex (male to female ratio) & $33(18-55)$ \\
\hline Age (years) & $60(50-72)$ \\
\hline Body weight (kg) & $18(90 \%)$ \\
\hline Antecedent events† (total) & $10(50 \%)$ \\
\hline Diarrhoea & $5(25 \%)$ \\
\hline Respiratory infection & $3(15 \%)$ \\
\hline Fever & $7(3-30)$ \\
\hline Days from antecedent events to weakness & $7(2-12)$ \\
\hline Days between onset of weakness and & \\
admission* & \\
\hline Neurological deficits at entry & $20(100 \%)$ \\
\hline Weakness in arms and legs & $12(60 \%)$ \\
\hline Cranial nerve deficits & $20(100 \%)$ \\
\hline Decreased deep tendon reflexes & $5(25 \%)$ \\
\hline Sensory involvement & $19(95 \%)$ \\
\hline GBS disability score & $1(5 \%)$ \\
\hline 4 & $20(0-29)$ \\
\hline Severity of weakness (MRC sum score) & $11(55 \%)$ \\
\hline
\end{tabular}

*Median (range).

†Symptoms of an infection in the 4 weeks preceding the onset of weakness.

‡GBS disability score $(0-6)=0$ : healthy state; 1 : minor symptoms and capable of running; 2: able to walk $10 \mathrm{~m}$ or more without assistance but unable to run; 3: able to walk $10 \mathrm{~m}$ across an open space with help; 4: bedridden or chairbound ; 5 : requiring assisted ventilation for at least part of the day; 6: dead.

GBS, Guillain-Barré syndrome; MRC, Medical Research Council.

\section{RESULTS}

\section{Patients and hospital controls}

The demographic and clinical characteristics of the 20 patients with GBS are given in table 1. The median age of the patients with GBS was 33 years (range 18-55); median body weight was $60 \mathrm{~kg}$ (IQR $55-65 \mathrm{~kg}$; range $50-72 \mathrm{~kg}$ ) and $13(65 \%)$ patients were male (figure 1). On admission and before the start of SVPE, all 20 patients with GBS were unable to walk independently (GBS disability score, 4). One patient required mechanical ventilation from the second day after the onset of weakness; SVPE was started on the fourth day of mechanical ventilation (patient 9 , figure 1 ). Two of the 19 patients who did not require mechanical ventilation at the start of the study required mechanical ventilation on the second day after initiation of SVPE (patients 11 and 19, 11 and 2 days after the onset of weakness, respectively; figure 1). The median MRC sum score for the limb muscles in all 20 patients was 20 (IQR 0-29; range 


\begin{tabular}{lllllllllllllllllllllll}
\hline Patients & 1 & 2 & 3 & 4 & 5 & 6 & 7 & 8 & 9 & 10 & 11 & 12 & 13 & 14 & 15 & 16 & 17 & 18 & 19 & 20 \\
\hline Sex/age & $\mathrm{M}$ & $\mathrm{F}$ & $\mathrm{F}$ & $\mathrm{F}$ & $\mathrm{F}$ & $\mathrm{M}$ & $\mathrm{M}$ & $\mathrm{M}$ & $\mathrm{M}$ & $\mathrm{M}$ & $\mathrm{M}$ & $\mathrm{F}$ & $\mathrm{M}$ & $\mathrm{M}$ & $\mathrm{M}$ & $\mathrm{M}$ & $\mathrm{F}$ & $\mathrm{F}$ & $\mathrm{M}$ & $\mathrm{M}$ \\
& 45 & 33 & 42 & 22 & 25 & 47 & 30 & 18 & 22 & 33 & 55 & 47 & 30 & 24 & 43 & 19 & 48 & 46 & 22 & 35 \\
\hline MRC entry & 29 & 28 & 1 & 4 & 20 & 0 & 34 & 30 & 0 & 0 & 0 & 26 & 20 & 28 & 34 & 0 & 26 & 36 & 0 & 20
\end{tabular}

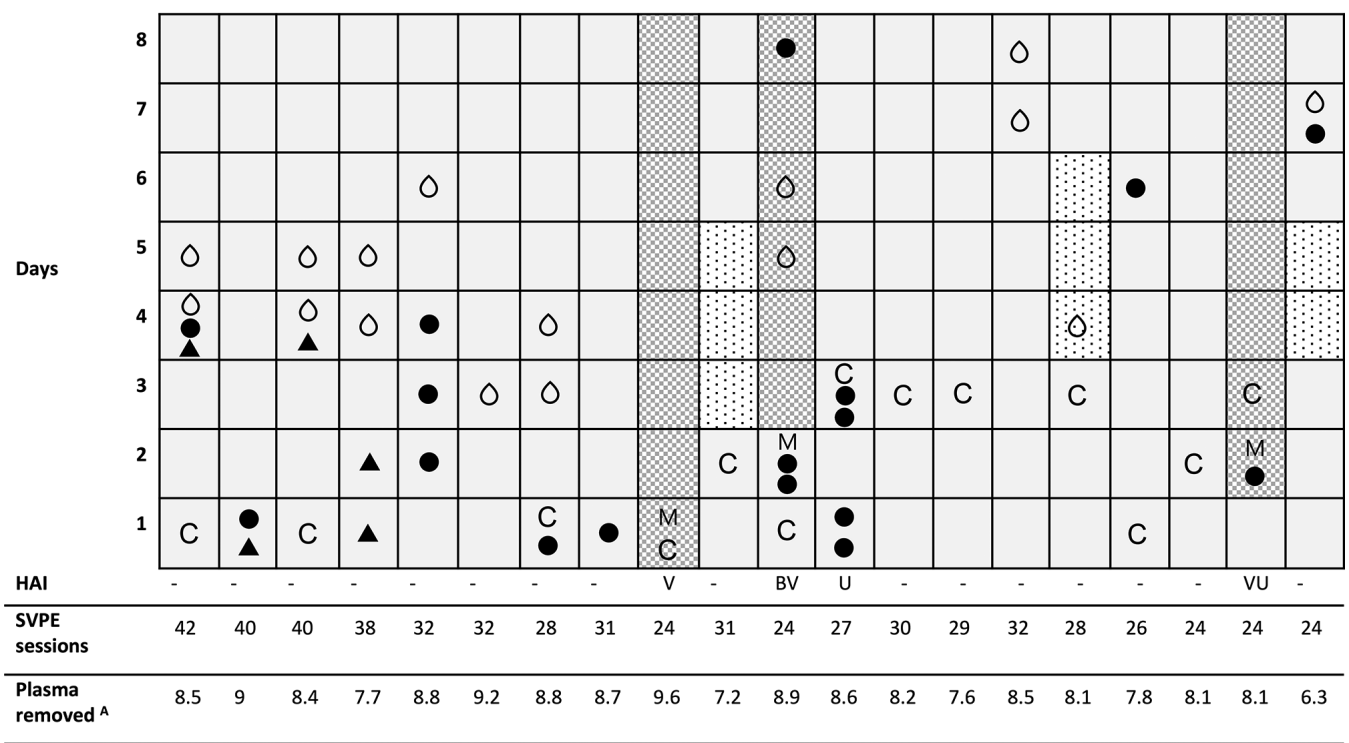

Figure 1 Feasibility of SVPE and associated complications for the 20 individual patients with GBS. ${ }^{A}$ Measured in litres. B, central line-associated blood stream infection; C, urinary catheterisation; CVC, central venous catheter; GBS, Guillain-Barré syndrome; HAl, hospital-acquired infection; M, onset of mechanical ventilation; MRC, Medical Research Council; SVPE: small volume plasma exchange; $\mathrm{U}$, catheter-associated urinary tract infection; $\mathrm{V}$, ventilator-associated pneumonia, $\mathbf{O}$, spell of hypotension (systolic blood pressure $<90 \mathrm{~mm} \mathrm{Hg}$ ); $\mathrm{O}$, CVC insertion site bleeding; $\boldsymbol{\Lambda}$, hypersensitivity to fresh frozen plasma, shaded squares: fever due to bacterial infection, dotted squares: fever due to suspected viral infection.

0-36; figure 1). Symptoms of a preceding infection in the 4 weeks before the onset of weakness were present in $18(90 \%)$ patients with GBS, of whom $10(50 \%)$ had diarrhoea. Median duration from admission to start of SVPE was 2 days (IQR 2-3 days; range 0-7 days). Median duration to nadir from the onset of weakness was 5 days (range 1-13 days). Electrodiagnostic nerve conduction studies (NCS) indicated $15(75 \%)$ patients had an axonal subtype and $5(25 \%)$ patients had a demyelinating subtype of GBS. Median duration from onset of weakness to NCS examination was 10 days (range 4-16 days). All patients had albuminocytological dissociation in cerebrospinal fluid (CSF) analysis (CSF protein level $>45 \mathrm{mg} / \mathrm{dL}$ in combination of CSF cell count $<50$ per $\mu \mathrm{L}$ ); median $\mathrm{CSF}$ protein was $166 \mathrm{mg} / \mathrm{dL}$ (range $117-253 \mathrm{mg} / \mathrm{dL}$ ). Median duration from onset of weakness to CSF examination was 11 days (range 4-17 days).

Median age of the 24 hospital control patients without GBS was 44 years (IQR 25-57; range 18-74); 10 $(42 \%)$ were male. Age and gender distribution were not significantly different compared with the 20 patients with GBS ( $\mathrm{p}=0.2155, \mathrm{p}=0.1434$, respectively). The diagnoses for these 24 patients were: brain tumour $(n=5)$, transverse myelitis $(n=5)$, head trauma after road traffic accident $(n=3)$, viral meningoencephalitis $(n=2)$, myasthenia gravis $(n=2)$, compressive cervical myelopathy $(n=2)$, cerebrovascular accident $(n=2)$, motor neuron disease $(n=1)$, electrolyte imbalance $(n=1)$ and status epilepticus $(n=1)$.

\section{Primary endpoints}

One patient with GBS treated with SVPE developed severe sepsis, possibly due to SVPE-related CLABSI (SVPE window-period blood culture revealed methicillin-resistant Staphylococcus aureus). This patient required intravenous fluid, noradrenalin infusion and intravenous antibiotics, but eventually improved (patient 11, figure 1). This patient also had signs and symptoms suggestive of aspiration pneumonia and VAP; Streptococcus spp. was isolated from pulmonary aspirates. Further laboratory results revealed dyselectrolytaemia, anaemia and hypoalbuminaemia. No patients experienced deep vein thrombosis due to the CVC for SVPE. Fifteen (75\%) of the 20 patients met the primary endpoint of feasibility, defined as the ability to remove at least $8 \mathrm{~L}$ of plasma in 8 days. The median volume of plasma removed was $8.5 \mathrm{~L}$ (IQR 7.9-8.8 L; range $6.3-9.6 \mathrm{~L}$; figure 1 ). The median $\mathrm{PE}$ rate was $140 \mathrm{~mL} / \mathrm{kg}$ bodyweight (IQR $125-155 \mathrm{~mL} / \mathrm{kg}$; range $110-175 \mathrm{~mL} / \mathrm{kg})$ over 8 days and $16(80 \%)$ patients had a PE rate $>120 \mathrm{~mL} / \mathrm{kg}$ (table 2 ).

\section{Secondary endpoints}

Infections among SVPE-treated patients with GBS and hospital controls

Among the 20 patients with GBS treated with SVPE, six $(30 \%)$ had fever during SVPE (figure 1, online supplementary figure 1), including two (10\%) patients with leucocytosis who were diagnosed with HAI (VAP and 
Table 2 Treatment characteristics and complications associated with SVPE in the 20 patients with GBS

\begin{tabular}{|c|c|}
\hline Characteristic/complication & Values \\
\hline \multicolumn{2}{|l|}{ Treatment characteristics } \\
\hline No of sessions of SVPE per patient* & $30(24-42)$ \\
\hline $\begin{array}{l}\text { Volume of plasma removed per } \\
\text { patient* }\end{array}$ & $8.4(6.3-9.6)$ \\
\hline Plasma exchange rate $(\mathrm{mL} / \mathrm{kg})^{\star}$ & $140(110-175)$ \\
\hline $\begin{array}{l}\text { Time between hospital admission } \\
\text { and SVPE (days)* }\end{array}$ & $8(5-10)$ \\
\hline $\begin{array}{l}\text { Time between onset of weakness } \\
\text { and start of SVPE (days)* }\end{array}$ & $8(5-10)$ \\
\hline $\begin{array}{l}\text { Need to stop SVPE due to poor } \\
\text { haemodynamic tolerance }\end{array}$ & $0 / 20(0 \%)$ \\
\hline $\begin{array}{l}\text { Need for blood transfusion for } \\
\text { anaemia }\end{array}$ & $1 / 20(5 \%)$ \\
\hline $\begin{array}{l}\text { Reduction of anticoagulant drug } \\
\text { dose for bleeding }\end{array}$ & $3 / 20(15 \%)$ \\
\hline $\begin{array}{l}\text { Temporary withdrawal of antiplatelet } \\
\text { drug for bleeding }\end{array}$ & $4 / 20(20 \%)$ \\
\hline $\begin{array}{l}\text { Increased anticoagulant drug dose } \\
\text { to continue SVPE }\end{array}$ & $1 / 20(5 \%)$ \\
\hline CVC blockade/replacement & $0 / 20(0 \%)$ \\
\hline \multicolumn{2}{|l|}{ Complications during SVPE } \\
\hline \multicolumn{2}{|l|}{ Infection } \\
\hline Leucocytosis & $7 / 20(35 \%)$ \\
\hline CLABSI† & 6.25 \\
\hline VAP† & 136.4 \\
\hline CAUTI† & 40 \\
\hline Severe sepsis & $1 / 20(5 \%)$ \\
\hline Antimicrobial agents used & $6 / 20(30 \%)$ \\
\hline \multicolumn{2}{|l|}{ Bleeding and coagulation } \\
\hline Bleeding from CVC insertion site & $10 / 20(50 \%)$ \\
\hline Bleeding from mucosal area & $3 / 20(15 \%)$ \\
\hline Prolonged BT (BT >10 min) & $0 / 20(0 \%)$ \\
\hline Prolonged CT (CT >15 min) & $0 / 20(0 \%)$ \\
\hline Prolonged PT $(\mathrm{PT}>14 \mathrm{~s})^{\star}$ & $6 / 20(30 \%)(15-19 s)$ \\
\hline Prolonged aPTT $(\mathrm{aPTT}>40 \mathrm{~s})^{*}$ & $3 / 20(15 \%)(51-240 \mathrm{~s})$ \\
\hline \multicolumn{2}{|l|}{ Other complications } \\
\hline Saline responsive hypotension & $10 / 20(50 \%)$ \\
\hline Anaemia $(\mathrm{Hb}<8 \mathrm{~g} / \mathrm{L})$ & $2 / 20(10 \%)$ \\
\hline $\begin{array}{l}\text { Thrombocytopaenia } \\
\left.\text { (Platelet count }<1.5 \times 10^{\wedge} \mathrm{g} / \mathrm{L}\right)^{*}\end{array}$ & $\begin{array}{l}6 / 20(30 \%) \\
\left(0.79-1.3 \times 10^{\wedge} 9 / L\right)\end{array}$ \\
\hline $\begin{array}{l}\text { Jaundice (serum } \\
\text { bilirubin }>1.2 \mathrm{mg} / \mathrm{dL} \text { ) }\end{array}$ & $0 / 20(0 \%)$ \\
\hline $\begin{array}{l}\text { Renal impairment (serum } \\
\text { creatinine }>1.2 \mathrm{mg} / \mathrm{dL} \text { ) }\end{array}$ & $0 / 20(0 \%)$ \\
\hline $\begin{array}{l}\text { Hyponatraemia (serum } \\
\left.\mathrm{Na}^{+}<135 \mathrm{mEq} / \mathrm{L}\right)^{\star}\end{array}$ & 1/20 (5\%) (126 mEq/L) \\
\hline $\begin{array}{l}\text { Hypocalaemia } \\
\left(\text { serum } \mathrm{K}^{+}<3.5 \mathrm{mEq} / \mathrm{L}\right)^{*}\end{array}$ & $3 / 20$ (15\%) (2.6-3.2 mEq/L) \\
\hline $\begin{array}{l}\text { Hypoalbuminaemia (serum } \\
\text { albumin }>35 \mathrm{gm} / \mathrm{L})^{*}\end{array}$ & $4 / 20(20 \%)(26-32 \mathrm{gm} / \mathrm{L})$ \\
\hline
\end{tabular}

Continued

\begin{tabular}{ll}
\hline Table 2 Continued & \\
\hline Characteristic/complication & Values \\
\hline $\begin{array}{l}\text { Hypocalcaemia } \\
\left(\text { serum } \mathrm{Ca}^{+}<2.2 \mathrm{mmol} / \mathrm{L}\right)^{*}\end{array}$ & $\begin{array}{l}3 / 20(15 \%)(1.89-1.98 \\
\mathrm{mmol} / \mathrm{L})\end{array}$ \\
$\begin{array}{l}\text { Hypomagnesaemia } \\
\left(\text { serum } \mathrm{Mg}^{+}<75 \mathrm{mEq} / \mathrm{L}\right)^{*}\end{array}$ & $1 / 20(5 \%)(73 \mathrm{mEq} / \mathrm{L})$ \\
$\begin{array}{l}\text { Hypersensitivity/transfusion } \\
\text { reaction to FFP }\end{array}$ & $4 / 20(20 \%)$ \\
\hline
\end{tabular}

*Exact value or range, which is appropriate.

†Rate per 1000 device days.

APTT, activated partial thromboplastin time; BT, bleeding time; $\mathrm{CT}$, clotting time; CAUTI, catheter-associated urinary tract infection; CLABSI, central line-associated bloodstream infection; CVC, central venous catheter; FFP, fresh frozen plasma; GBS, Guillain-Barré syndrome; $\mathrm{Hb}$, haemoglobin; PT, prothrombin time; SVPE, small volume plasma exchange; VAP, ventilator-associated pneumonia.

CAUTI in one patient; VAP in one patient). In three out of four $(20 \%)$ patients with fever without leucocytosis, fever subsided within 2-3 days without antimicrobial therapy (figure 1). The remaining patient with fever without leucocytosis had microbiological evidence of both CLABSI and VAP (patient 11, figure 1). In all other 14 patients with GBS, no fever was documented during the course of SVPE until the 10th day of SVPE (second day after removal of the CVC for SVPE). Five of these 14 patients had leucocytosis, but no site-specific HAI could be detected. However, one of the nine patients without fever but leucocytosis fulfilled the criteria for CAUTI (patient 12, figure 1). All three patients who required mechanical ventilation subsequently developed VAP; 2 of the 13 patients who required a urinary catheter developed a CAUTI (patient 11, figure 1). No patients died during the 6 months follow-up.

All 24 hospital control patients without GBS required mechanical ventilation and an indwelling urinary catheter. Of these patients, 22 (92\%) patients had fever, of whom $15(63 \%)$ had leucocytosis; a diagnosis of a specific HAI could be made 14 of these 15 patients (CLABSI in 2, CAUTI in 1, VAP in 11) and $4(17 \%)$ fulfilled the criteria for severe sepsis (online supplementary figure 1). Seven (29\%) of the 24 hospital control patients had fever without leucocytosis. In two of these seven patients, a specific HAI was diagnosed (CAUTI and VAP in one, and VAP in one). In two hospital control patients, no fever was documented until day 10 after first placement of the CVC, but leucocytosis was present and no site-specific HAI could be detected (online supplementary figure 1).

The rates of CLABSI, CAUTI and VAP per 1000 device days in the SVPE-treated patients with GBS were 6.25, 19.2 and 40 compared with $10.4,10.4$ and 67.7 for the hospital control patients without GBS, respectively. The relative risks of CLABSI, CAUTI and VAP associated with SVPE were 0.6, 1.2 and 1.8, respectively, compared with hospital control patients. The rates of CLABSI, CAUTI and VAP were comparable between SVPE-treated patients with GBS and hospital control patients $(p>0.05)$. 
SVPE $(n=20)$

Non SVPE $(n=24)$

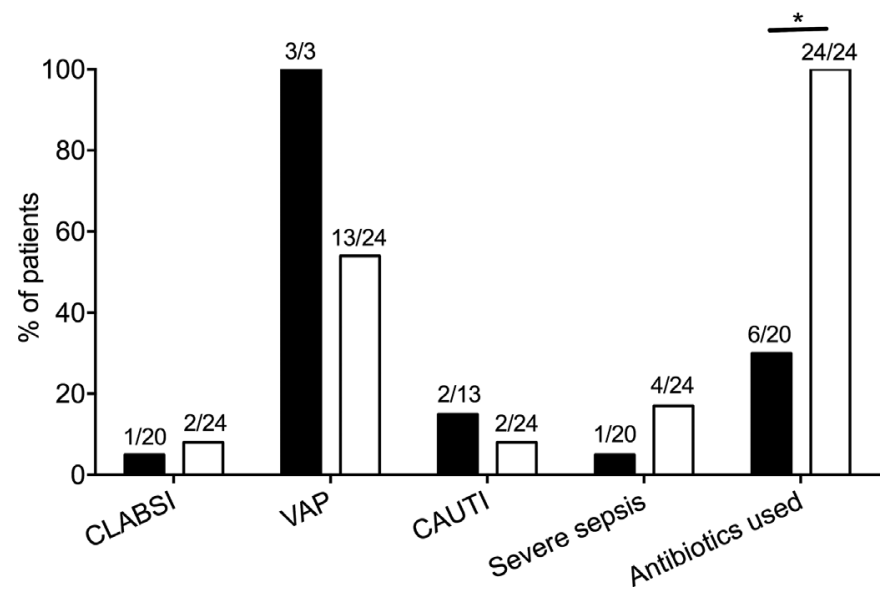

Figure 2 Hospital-acquired infections and use of antibiotics in the 20 patients with GBS receiving SVPE compared with the 24 hospital control patients without GBS treated in the same ICU and HDU with a CVC who did not receive SVPE. SVPE $(n=20): 20$ patients with GBS aged $\geq 18$ years old who were bedbound (GBS disability score $\geq 4$ ) received SVPE within 2 weeks of the onset of weakness. $\square$ Non-SVPE $(n=24)$ : 24 patients aged $\geq 18$ years old with a diagnosis other than GBS who required a CVC for $>2$ to $\leq 8$ calendar days after admission to the same ICU and HDU units in the same period as the patients with GBS received SVPE. ${ }^{*} \mathrm{P}<0.0001$. CLABSI, central line-associated blood stream infection; CAUTI, catheter-associated urinary tract infection; CVC, central venous catheter; GBS, Guillain-Barré syndrome; ICU, intensive care unit; SVPE, small volume plasma exchange; VAP, ventilator-associated pneumonia.

Antimicrobial agents were used more frequently in the hospital control patients $(p<0.0001$; figure 2$)$. The SIRs for CLABSI, CAUTI and VAP for SVPE-treated patients with GBS were $0.6,1.8$ and 1.9 , respectively.

\section{Other secondary endpoints}

Ten $(50 \%)$ of the 20 patients treated with SVPE experienced transient hypotension during SVPE, which was corrected by infusion of $200-300 \mathrm{~mL}$ crystalloid saline (figure 1). Minor bleeding through the CVC insertion site (excluding at the time of insertion) was observed in 10 of 20 patients ( $50 \%$; figure 1 ); these bleeds required a pressure pack. Reduction of the anticoagulant dose along with a pressure pack was required in 3 of 20 patients, who all had a prolonged prothrombin time (PT). Three patients had single episode of haemorrhage through the urinary catheter: one was diagnosed with a CAUTI with normal coagulation profile, one had a prolonged PT, the other had sterile haematuria with normal PT. Overall, PT and activated partial thromboplastin time (aPTT) were prolonged in 4 of 20 patients and only PT was prolonged in 2 of 20 patients. Clotting time (CT) and bleeding time were not prolonged in any patient. One patient developed anaemia $(\mathrm{Hb}, 8 \mathrm{~g} / \mathrm{dL})$ at the end of SVPE; this patient also had severe sepsis and required one unit of blood transfusion (patient 11, figure 1). CVC blockages were not observed in any SVPE-treated patients with GBS. One patient with increased clotting tendency who required an increased dose of low-molecular-weight heparin had shortened CT $(<50 \%$ of upper limit of normal $)$, though PT was normal (patient 10, figure 1).

The neurological outcomes of the SVPE-treated patients with GBS at 6 months in terms of neurological scores are given in table 3 . Median time to recover the ability to walk unaided was 4 weeks (figure 3 ). Fourteen $(70 \%)$ of the 20 patients had an improvement in GBS disability score of one or more grades at 4 weeks after the onset of SVPE. At 1 month, 12 patients $(60 \%)$ were able to walk unaided, 2 patients (10\%) were able to walk aided and 6 $(30 \%)$ patients were bedbound, of whom 3 still required

Table 3 Neurological outcomes of the 20 patients with GBS after SVPE

\begin{tabular}{lllll}
\hline Clinical outcome & 1 month & 2 months & 3 months & 6 months \\
\hline Cranial nerve involvement & $7 / 20(35 \%)$ & $6 / 20(30 \%)$ & $4 / 20(20 \%)$ & $2 / 20(10 \%)$ \\
Autonomic involvement & $3 / 20(15 \%)$ & $3 / 20(15 \%)$ & $0 / 20(0 \%)$ & $0 / 20(0 \%)$ \\
Sensory dysfunction & $1 / 20(5 \%)$ & $1 / 20(5 \%)$ & $1 / 20(5 \%)$ & $1 / 20(5 \%)$ \\
GBS disability score & $0=0$ & $0=1$ & $0=1$ & $0=2$ \\
& $1=3$ & $1=6$ & $1=7$ & $2=7$ \\
& $2=9$ & $2=6$ & $3=1$ & $3=3$ \\
& $3=2$ & $3=1$ & $4=5$ & $4=3$ \\
MRC sum score† & $4=3$ & $4=5$ & $5=0$ & $5=0$ \\
ONLS & $5=3$ & $5=1$ & $53(6-60)$ & $58(22-60)$ \\
R-ODS & $47(0-60)$ & $49(0-60)$ & $3(0-12)$ & $2(0-10)$
\end{tabular}

*GBS disability score (0-6)=0: healthy state, 1 : minor symptoms and capable of running, 2: able to walk $10 \mathrm{~m}$ or more without assistance but unable to run, 3: able to walk $10 \mathrm{~m}$ across an open space with help, 4: bedridden or chairbound , 5: requiring assisted ventilation for at least part of the day, 6: dead.

†Median (range).

GBS, Guillain-Barré syndrome; MRC, Medical Research Council; ONLS, Overall Neuropathy Limitation Scale ${ }^{22}$; R-ODS, Rash-built Overall Disability Score ${ }^{23}$; SVPE, small volume plasma exchange. 


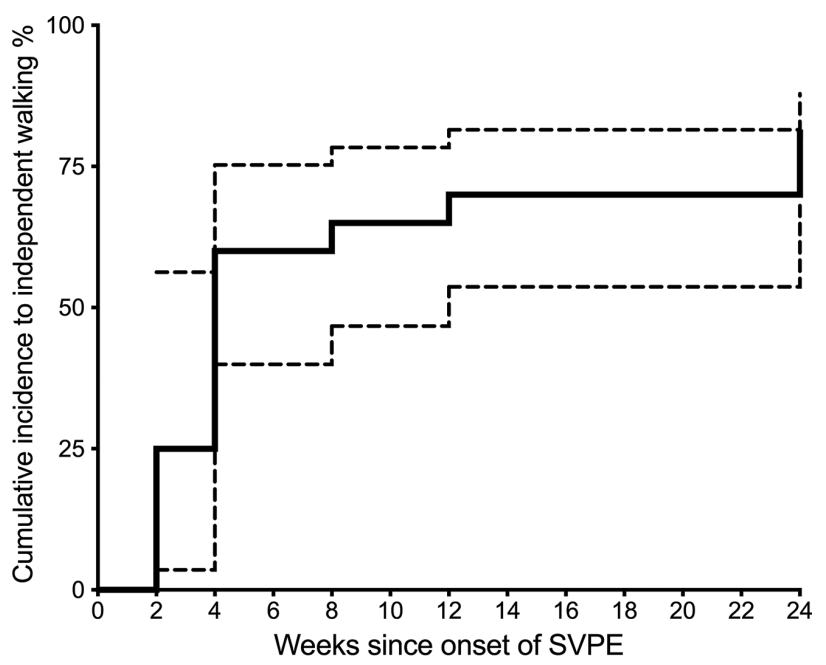

$\begin{array}{lllll}\text { No. at Risk } & 20 & 15 & 8 & 7\end{array}$

Figure 3 Kaplan-Meier estimate (with 95\% confidence limits) of the cumulative incidence of restoration of independent walking ability in patients with Guillain-Barré syndrome treated with small volume plasma exchange (SVPE).

mechanical ventilation. At 3 months, 14 (70\%) patients were able to walk unaided, $1(5 \%)$ could walk with aid and $5(25 \%)$ patients were bedbound. At 6 months, 14 $(70 \%)$ patients were able to walk unaided, $3(5 \%)$ could walk with aid and $3(15 \%)$ remained bedbound (table 3 ).

\section{Other relevant clinical and laboratory findings}

Allergic/transfusion reaction to FFP was observed in four patients with GBS treated with SVPE (figure 1). These transfusion reactions presented as an itchy erythematous skin rash (three patients), fever (two patients), hypotension (one patient) following transfusion of FFP; all of these reactions were managed with oral antihistamine (and intravenous saline in one patient) without further complications.

The other documented haematological and biochemical abnormalities were hypoalbuminaemia $(n=4)$, thrombocytopaenia $(n=6)$, hyponatraemia $(n=1)$, hypocalaemia $(n=3)$, hypomagnesaemia $(n=1)$, hypocalcaemia $(n=3)$; (table 2).

\section{Immunoglobulin dosage admitted by FFP}

During SVPE the median volume of FFP administered per patient with GBS as replacement fluid was $6000 \mathrm{~mL}$ (range 5000-6000 mL). Considering the normal plasma IgG level of $11.20 \mathrm{mg} / \mathrm{mL}$ (range $6.9-17.6 \mathrm{mg}$ ), ${ }^{36}$ SVPEtreated patients with GBS received IgG dose of median $0.9 \mathrm{~g} / \mathrm{kg}$ (range $0.6-1.3 \mathrm{~g} / \mathrm{kg}$ ).

\section{DISCUSSION}

\section{Principal findings}

This study suggests SVPE may represent a safe and feasible alternative to conventional PE for patients with severe GBS in resource-limited settings. Of the 20 patients in this study, one (5\%) experienced an SAE (severe sepsis due to probable CLABSI). The rate of SAE was not significantly higher than the hospital control group without GBS with a CVC, and no patients had a CVC-related thromboembolic event in patients with SVPE. We were able to remove the prespecified target volume $(8 \mathrm{~L})$ of plasma as the target primary endpoint of feasibility in 15/20 (75\%) patients with GBS. Median PE volume and rate during SVPE were $8.4 \mathrm{~L}$ and $140 \mathrm{~mL} / \mathrm{kg}$, respectively. Minor adverse effects included transient hypotension during SVPE in 50\% $(10 / 20)$, minor haemorrhage from CVC insertion site in $50 \%(10 / 20)$, transfusion reaction to FFP in $20 \%(4 / 20)$, and hypoalbuminaemia, anaemia and electrolyte imbalance in 20\% (4/20) of patients. An improvement of at least one grade on the GBS disability score was observed for $14 / 20(70 \%)$ patients at 4 weeks after the initiation of SVPE. No patients died.

\section{Comparison with baseline hospital control patients and standard/modified PE}

With respect to HAIs, no significant differences were observed in the frequency of CLABSI, severe sepsis, VAP or CAUTI between the SVPE-treated patients with GBS and 24 hospital control patients without GBS treated using a CVC in the same ICU or HDU (figure 2). However, antimicrobial agents were used more frequently, usually prophylactically, in the hospital control patients compared with the patients with GBS treated with SVPE $(p<0.0001$; figure 2). The probability of detecting micro-organisms in clinical infections may have been reduced due to overzealous use of antibiotics in the hospital control patients. Early trials of PE in patients with GBS showed $34 \%$ of patients develop severe infections. ${ }^{71}$ Subsequently, another large trial documented septicaemia in $19 \%$ of patients. ${ }^{5}$ However, the rates of CLABSI were not reported.

A previous randomised controlled trial (RCT) on GBS from the USA showed a beneficial effect with PE rate of $40-50 \mathrm{~mL} / \mathrm{kg} / \mathrm{session}$, for three to five sessions in 7-14 days, which comes to a total PE volume of $120-250 \mathrm{~mL} /$ kg. ${ }^{7}$ The first French RCT on adult patients with GBS showed beneficial effect of four PE sessions (two plasma volume (3.5 L) per PE session) over 8 days and in range, 6-12L plasma was removed per patient. ${ }^{4}$ Subsequent French RCT with PE dose escalation showed, two PE sessions (1.5 plasma volume per PE session) are beneficial in mild to moderate GBS cases but less effective than four PE sessions in severe GBS cases and six PE sessions are as effective as four PE sessions in severe cases of GBS. ${ }^{5}$ In this RCT, the exact total plasma volume exchanged per patient was not mentioned, but the authors indicated that the rate of $\mathrm{PE}$ was $40 \mathrm{~mL} / \mathrm{kg}$ body weight per PE session. As to that a $60-70 \mathrm{~kg}$ person should have an exchange of 2.4-2.8 $\mathrm{L}$ per session and the therapeutic range of plasma volume to be exchanged would be $5.6-11.2 \mathrm{~L} \mathrm{~mL}$ (two to four PE sessions).

During the piloting of the SVPE procedure we assessed that removal of $1 \mathrm{~L}$ of patient plasma could be feasible in 
a day. Therefore, we defined our target plasma volume of $8 \mathrm{~L}$ to be removed in 8 days. The median total PE volume and rate in SVPE was $8.4 \mathrm{~L}$ and $140 \mathrm{~mL} / \mathrm{kg}$, which is at the lower range as compared with both the French and American RCT on PE for adult patients with GBS. We were able to remove $>120 \mathrm{~mL} / \mathrm{kg}$ plasma in $80 \%$ of patients, which should provide a therapeutic effect. ${ }^{37}$ Notably, the body weight of our patients may be lower than that of patients in Western countries. In addition, SVPE was complete within 8 days, shorter than the usual time required for a full session of PE (10-12 days).

Replacement fluid used in SVPE was FFP. We have several justifications in favour of using FFP instead of human albumin or other available colloidal solutions available in Bangladesh. First, FFP is safe in terms of microbiological safety since stringent screening for viral and bacterial contamination was performed before infusion. Second, in contrast to human albumin and colloid solutions, FFP contains normal human IgG that could contribute to the beneficial immunotherapeutic effect in GBS. FFP was previously used as replacement fluid in large PE trials, quintessentially with the same volume (half the volume of replacement fluid) we used in SVPE. ${ }^{4}$ SVPE-treated patients with GBS received approximately half the amount of IgG from the FFP used as replacement fluid compared with the total IVIg doses traditionally used in GBS (2g/ $\mathrm{kg}$ ). Third, FFP contains all human plasma proteins that help preservation of plasma colloid osmotic pressure and prevents formation of oedema and hypotension. Lastly, FFP is much cheaper than commercial human albumin.

In each day, three units of FFP were transfused as replacement fluid after the last session of SVPE and in the initial two to three sessions, normal saline was used as replacement fluid. This was done to achieve the maximum immunotherapeutic effect of FFP as SVPE was not resumed before the next day and the $\operatorname{IgG}$ in FFP remained in the circulation overnight for a longer period of time (10-12 hours). However, due to long half life of IgG, a substantial amount of IgG present in FFP was probably washed away due to repeated plasma removal both during SVPE and by conducting standard PE.

In GBS, treatment with modified methods of PE done previously, were device based and done on limited number of patients with GBS. In one study on 25 patients with GBS from India, daily removal of small volume of plasma (10-15 mL plasma $/ \mathrm{kg}$ body weight) for duration of median 3 days using traditional PE machine was shown to be clinically beneficial. ${ }^{38}$ In another study from the same country, 12 patients with GBS were treated with PE over 10 days using different PE-machine kit (REF627 kit from Haemonetics on MCS+machine) where authors claimed clinical improvement, however, the main focus was on cost-effectiveness and the total plasma volume exchanged per patient was not mentioned. ${ }^{39}$ Nevertheless, these methods are based on specific devices those are not in common practice, nor the trained personnel for these are available in the low-income and middle-income countries.
Important observations in terms of secondary endpoints were transient hypotension, transfusion reaction to FFP and minor bleeding through the CVC insertion site. Hypotension is a common complication during traditional PE that affects nearly half of patients. ${ }^{5}$ Spells of hypotension during SVPE were more frequent during the 3-4days after initiation of SVPE, and could be easily corrected by rapid infusion of $300-400 \mathrm{~mL}$ saline (figure 1). The hypotension could possibly be explained by hypovolaemia due to drawing blood or as a result of the compromised autonomic nervous system in patients with GBS. As SVPE proceeded, hypotensive spells were encountered less frequently despite drawing the same volume of blood, which may in part be explained by adaptation of the vasomotor system or recovery from autonomic dysfunction. Minor bleeding through the CVC insertion site occurred in $50 \%$ of patients and could be controlled by applying a simple pressure pack over the CVC insertion site in most cases; mild prolonged PT was noted in $30 \%$ $(3 / 10)$ patients. However, spontaneous bleeding usually occurs if the PT is more than 2.5 times prolonged and PC is $<0.50 \mathrm{lac} / \mu \mathrm{L} .{ }^{40}$ Movement of the limb where the $\mathrm{CVC}$ was placed may have caused traction on the CVC and contributed to local bleeding in the other seven patients. Haematuria is not uncommon in patients with a UTI, as may have occurred in one SVPE-treated patient; traumatic traction of the urinary catheter may cause haematuria in two other catheterized SVPE-treated patient taking oral aspirin, who had haematuria and sterile urine. We also monitored the major organ function and biochemical status of the patients treated with SVPE. No patients experienced hepatic or renal impairment. One patient developed anaemia and hypoalbuminaemia; this patient had severe sepsis, a common cause of anaemia and hypoalbuminaemia in critically ill patients admitted to an ICU (patient 11, figure 1). Electrolyte imbalances were detected in $15 \%$ of the SVPE-treated patients with GBS, and were mild, subclinical and easily corrected.

The median reported durations to recovery of independent walking in patients with GBS in large-scale RCTs after PE are 53, 52 and 70 days ${ }^{45}$; compared with 30 days in our patients treated with SVPE. Moreover, $60 \%$ of the patients with GBS treated with SVPE were able to walk independently at 4 weeks, whereas $20 \%$ of patients with GBS acquired independent walking ability at 4 weeks after traditional PE. However, these differences may possibly be due to the small sample size and variations in demographic and neurophysiological characteristics between cohorts. Finally, SVPE was completed in all 20 patients and no patients died.

\section{Limitations of SVPE}

SVPE is a time-consuming and labour-intensive procedure, which is a limitation. We used multiple thin-lumen tubing systems interconnected with a multichannel connector device, which may increase the chance of blood coagulating within the tubing system. Coagulation may require manipulation or replacement 
of the tubing to ensure free flow of blood and saline. Such handling could increase the chance of microbial contamination. A single continuous wide-lumen tubing system (SVPE kit) could resolve this problem. Most importantly, personnel conducting the SVPE procedure should maintain proper aseptic technique, which can sometimes be challenging in low-income and middle-income countries. Furthermore, other adaptations such as provision of a larger blood bag or increasing the number of days for SVPE could be considered to increase the PE rate.

\section{Clinical implications and future research}

Despite the limitations, our study showed that SVPE is a safe and feasible treatment for GBS in a resource-limited setting where IVIg or PE is either unavailable or unaffordable. Specifically, the poorest $20 \%$ of the world's population ( 1.8 billion people) who typically earn less than US $\$ 10$ per day and who are not covered by a national health insurance system may benefit. Considering the incidence of GBS is 2/100 000 in low-income and middle-income countries, approximately 40000 patients could potentially benefit from SVPE every year, worldwide. In the future, a multicentre RCT is required to assess the clinical efficacy of SVPE for patients with GBS. If proven effective, SVPE could be an affordable and easily available alternative PE technique in low-income countries for patients with GBS and other disorders, who at present cannot afford standard PE due to its high cost and unavailability.

\section{Author affiliations}

${ }^{1}$ Department of Medical Microbiology and Infectious Diseases, Erasmus University Medical Center, Rotterdam, The Netherlands

${ }^{2}$ Laboratory Sciences and Services Division (LSSD), The International Centre for Diarrhoeal Disease Research (icddr,b), Dhaka, Bangladesh

${ }^{3}$ Department of Intensive Care Medicine, Uttara Adhunik Medical College \& Hospital, Dhaka, Bangladesh

${ }^{4}$ Department of Intensive Care, Erasmus University Medical Center, Rotterdam, The Netherlands

${ }^{5}$ Department of Neurology, Erasmus University Medical Center, Rotterdam, The Netherlands

${ }^{6}$ Departments of Neurology and Immunology, Erasmus University Medical Center, Rotterdam, The Netherlands

${ }^{7}$ Department of Neurology, National Institute of Neurosciences (NINS) and Hospital, Dhaka, Bangladesh, National Institute of Neuroscience (NINS), Dhaka, Bangladesh

Acknowledgements The icddr,b acknowledges with gratitude the contributions of the government of Bangladesh, Global Affairs Canada (GAC), Swedish International Development Cooperation Agency (Sida) and Department for International Development, UK (DFID). Md Ekhlas Mia and Smrity Akhter assisted this study in a full-time capacity. We are grateful to all of the neurologists from the NINS who referred their patients to us and K. S. Fahim for his support in preparation of the diagrams in this article.

Contributors $\mathrm{BI}, \mathrm{PAvD}, \mathrm{BCJ}, \mathrm{QDM}, \mathrm{Zl}$ and HPE conceived the study design and sample size of the study. MvdJ, MCV, SR and HPE contributed to the infection safety guidelines in the study design. BI and QDM conducted the study and BI collected and analysed the data and drafted the manuscript. All authors critically revised the manuscript, and read and approved the final manuscript.

Funding This study was funded by two competitive research grants: (1) The GBS/ CIDP Foundation International GBS grant (major contribution) (2) The Fondation Mérieux: Small Grants Program 2014 (partial contribution).
Competing interests None declared.

Patient consent Obtained.

Ethics approval The Institutional Review Board (IRB) of the icddr,b, comprised an Ethical Review Committee (ERC) and Research Review Committee (RRC), reviewed and approved this study protocol on 09/12/2015 (reference number: PR-15086, version no 3).

Provenance and peer review Not commissioned; externally peer reviewed.

Data sharing statement Extra data can be accessed via the Dryad data repository at http://datadryad.org/ with the doi: 10.5061/dryad.55nb389

Open access This is an open access article distributed in accordance with the Creative Commons Attribution Non Commercial (CC BY-NC 4.0) license, which permits others to distribute, remix, adapt, build upon this work non-commercially, and license their derivative works on different terms, provided the original work is properly cited, appropriate credit is given, any changes made indicated, and the use is non-commercial. See: http://creativecommons.org/licenses/by-nc/4.0/.

\section{REFERENCES}

1. Willison $\mathrm{HJ}$, Jacobs BC, van Doorn PA. Guillain-Barré syndrome. Lancet 2016;388:717-27.

2. Van Koningsveld R, Van Doorn PA, Schmitz PI, et al. Mild forms of Guillain-Barré syndrome in an epidemiologic survey in The Netherlands. Neurology 2000;54:620-5.

3. Asbury AK, Arnason BG, Adams RD. The inflammatory lesion in idiopathic polyneuritis. Its role in pathogenesis. Medicine 1969;48:173-215.

4. Anon. Efficiency of plasma exchange in Guillain-Barré syndrome: role of replacement fluids. French Cooperative Group on Plasma Exchange in Guillain-Barré syndrome. Ann Neurol 1987;22:753-61.

5. Anon. Appropriate number of plasma exchanges in Guillain-Barré syndrome. The French cooperative group on plasma exchange in Guillain-Barré Syndrome. Ann Neurol 1997;41:298-306.

6. Anon. Plasma exchange in Guillain-Barré syndrome: one-year followup. French Cooperative Group on Plasma Exchange in Guillain-Barré Syndrome. Ann Neurol 1992;32:94-7.

7. Anon. Plasmapheresis and acute Guillain-Barré syndrome. The Guillain-Barré syndrome Study Group. Neurology 1985;35:1096-104.

8. Greenwood RJ, Newsom-Davis J, Hughes RA, et al. Controlled trial of plasma exchange in acute inflammatory polyradiculoneuropathy. Lancet 1984;1:877-9.

9. Osterman PO, Fagius J, Lundemo G, et al. Beneficial effects of plasma exchange in acute inflammatory polyradiculoneuropathy. Lancet 1984;2:1296-9.

10. Hughes RAC, Swan AV, van Doorn PA. Cochrane Neuromuscular Group. Intravenous immunoglobulin for Guillain-Barré syndrome. Cochrane Database Syst Rev 2014;46.

11. Chevret S, Hughes RA, Annane D. Plasma exchange for GuillainBarré syndrome. Cochrane Database Syst Rev 2017;2:CD001798.

12. Hughes RA, Wijdicks EF, Barohn R, et al. Practice parameter: immunotherapy for Guillain-Barré syndrome: report of the Quality Standards Subcommittee of the American Academy of Neurology. Neurology 2003;61:736-40.

13. van der Meché FG, Schmitz PI. A randomized trial comparing intravenous immune globulin and plasma exchange in GuillainBarré syndrome. Dutch Guillain-Barré Study Group. N Engl J Med 1992;326:1123-9.

14. Islam MB, Islam Z, Farzana KS, et al. Guillain-Barré syndrome in Bangladesh: validation of Brighton criteria. J Peripher Nerv Syst 2016;21:345-51.

15. Islam Z, Jacobs BC, van Belkum A, et al. Axonal variant of GuillainBarre syndrome associated with Campylobacter infection in Bangladesh. Neurology 2010;74:581-7.

16. Ishaque T, Islam MB, Ara G, et al. High mortality from Guillain-Barré syndrome in Bangladesh. J Peripher Nerv Syst 2017;22:121-6.

17. Islam MB, Islam Z, Rahman $S$, et al. Small volume plasma exchange for Guillain-Barré syndrome in resource poor settings: a safety and feasibility study. Pilot Feasibility Stud 2017;3:40.

18. Asbury AK, Cornblath DR. Assessment of current diagnostic criteria for Guillain-Barré syndrome. Ann Neurol 1990;27 (suppl):S21-24.

19. Centers for Disease Control and Prevention. Bloodstream infection event (central line-associated bloodstream infection and noncentral line associated bloodstream infection. 2018 (accessed 8 Jun 2018).

20. Hughes RA, Newsom-Davis JM, Perkin GD, et al. Controlled trial prednisolone in acute polyneuropathy. Lancet 1978;2:750-3. 
21. Kleyweg RP, van der Meché FG, Schmitz PI. Interobserver agreement in the assessment of muscle strength and functional abilities in Guillain-Barré syndrome. Muscle Nerve 1991;14:1103-9.

22. Graham RC, Hughes RA. A modified peripheral neuropathy scale: the overall neuropathy limitations scale. J Neurol Neurosurg Psychiatry 2006;77:973-6.

23. van Nes SI, Vanhoutte EK, van Doorn PA, et al. Rasch-built Overall Disability Scale (R-ODS) for immune-mediated peripheral neuropathies. Neurology 2011;76:337-45.

24. Pronovost PJ, Goeschel CA, Colantuoni E, et al. Sustaining reductions in catheter related bloodstream infections in Michigan intensive care units: observational study. BMJ 2010;340:c309.

25. Flodgren G, Conterno LO, Mayhew A, et al. Interventions to improve professional adherence to guidelines for prevention of device-related infections. Cochrane Database Syst Rev 2013;3:Cd006559.

26. O'Grady NP, Alexander M, Burns LA, et al. Summary of recommendations: guidelines for the prevention of intravascular catheter-related infections. Clin Infect Dis 2011;52:1087-99.

27. Centers for Disease Control \& Prevention. Urinary Tract Infection (Catheter-Associated Urinary Tract Infection [CAUTI] and NonCatheter-Associated Urinary Tract Infection [UTI]) and Other Urinary System Infection [USI]) Events. 2018.

28. Centers for Disease Control \& Prevention. Pneumonia (Ventilatorassociated [VAP] and non-ventilator-associated Pneumonia [PNEU]) Event. 2018.

29. Centers for Disease Control \& Prevention. Identifying Healthcareassociated Infections (HAI) for NHSN Surveillance. 2018.

30. Centers for Disease Control \& Prevention. CDC/NHSN Surveillance definitions for specific types of infections. 2018.
31. The Dutch Guillain-Barre Study Group. Treatment of GuillainBarre syndrome with high-dose immune globulins combined with methylprednisolone: a pilot study. Ann Neurol 1994;35:749-52.

32. Garssen MP, van Koningsveld R, van Doorn PA, et al. Treatment of Guillain-Barré syndrome with mycophenolate mofetil: a pilot study. $J$ Neurol Neurosurg Psychiatry 2007;78:1012-3.

33. Stigler SM. The true title of Bayes's essay. Statistical Science 2013;28:283-8

34. Freedman LS, Spiegelhalter DJ, Parmar MK. The what, why and how of Bayesian clinical trials monitoring. Stat Med 1994;13:1371-83.

35. Resnic FS, Zou KH, Do DV, et al. Exploration of a bayesian updating methodology to monitor the safety of interventional cardiovascular procedures. Med Decis Making 2004;24:399-407.

36. Gonzalez-Quintela A, Alende R, Gude F, et al. Serum levels of immunoglobulins (IgG, $\lg A$, $\lg M)$ in a general adult population and their relationship with alcohol consumption, smoking and common metabolic abnormalities. Clin Exp Immunol 2008;151:42-50.

37. McKhann GM, Griffin JW, Cornblath DR, et al. Plasmapheresis and Guillain-Barré syndrome: analysis of prognostic factors and the effect of plasmapheresis. Ann Neurol 1988;23:347-53.

38. Tharakan J, Jayaprakash PA, lyer VP. Small volume plasma exchange in Guillain-Barre syndrome: experience in 25 patients. $J$ Assoc Physicians India 1990;38:550-3.

39. Iyer RR, Shah PH, Roy SS, et al. Reducing the economic burden in management of Guillain-Barre syndrome using modified plasmapheresis. Asian J Transfus Sci 2016;10:118-21.

40. Izak M, Bussel JB. Management of thrombocytopenia. F1000Prime Rep 2014;6. 